TP Periodica Polytechnica Mechanical Engineering

\author{
62(4), pp. 305-311, 2018 \\ https://doi.org/10.3311/PPme.12348 \\ Creative Commons Attribution (i)
}

RESEARCH ARTICLE

\section{The Effect of Rheology Model of an Activated Sludge on to the Predicted Losses by an Elbow}

\author{
Péter Csizmadia $^{1 *}$, Sára Till ${ }^{1}$
}

Received 04 April 2018; accepted after revision 26 July 2018

\begin{abstract}
This study presents a numerical investigation of flow and rheological behaviour of activated sludge. These materials are usually driven by pumps in wastewater treatment plants. Because of the correct sizing of the pipeline systems, which is of great importance from the point of view of efficiency, the friction losses and loss coefficients of the components have to be known. These are well-known in the case of Newtonian fluids but few data are available if the rheological properties are non-Newtonian. Three non-Newtonian models (Ostwald, Bingham, Herschel-Bulkley) are investigated related to the friction factor of a straight pipe, the loss coefficients of an elbow and to the pressure drop on this element. For our study the rheological data were used from the literature, where the same sample origin was diluted or concentrated to achieve three different TSS (total suspended solids) contents for the same sludge $(7.4 \mathrm{~g} / \mathrm{l}$; $6.2 \mathrm{~g} / \mathrm{l} ; 3.6 \mathrm{~g} / \mathrm{l}$ ). Moreover, modified Reynolds-number definitions are tested related to the non-Newtonian models in the case of the laminar, transition and turbulent regions.
\end{abstract}

\section{Keywords}

activated sludge, CFD simulation, loss coefficient, non-Newtonian flow, rheological parameters

\footnotetext{
${ }^{1}$ Department of Hydrodynamic Systems

Faculty of Mechanical Engineering,

Budapest University of Technology and Economics

H-1111 Budapest, Müegyetem rkp. 3., Hungary

*Corresponding author, e-mail: pcsizmadia@hds.bme.hu
}

\section{Introduction}

Knowing the hydrodynamic behaviour of sludge is essential to design and operate cost-efficient processes and machines. For system design computational fluid dynamics (CFD) modelling has to use the appropriate rheological models to predict the hydrodynamic behaviour accurately [1-3]. The sludge has non-Newtonian rheological characteristics meaning different behaviour from Newtonian fluids during flow in pipes, mixing and sedimentation processes [4]. Ratkovich et al. [1] reviewed the literature from the latest period and found that replacing the sludge viscosity with that of plain water is a very crude approximation and may cause intolerable deviations from realistic process behaviour.

There is a relatively large volume of published studies describing the flow of non-Newtonian substances in engineering applications, such as egg [5], fruit juice [6] and dense slurry from power plants [7]. By contrast, only a few data are available about activated sludge flow in hydrodynamic systems [8, 9]. However, for correct sizing of wastewater treatment plants (WWTPs) the friction losses and the loss coefficients of the components have to be known.

The most frequent non-Newtonian rheological models to describe sludge behaviour in steady state laminar flow are the Ostwald (power-law), the Bingham, the Herschel-Bulkley, the Casson, the Sisko, the Carreau and the Cross models [8].

The activated sludge technology can be applied by differently loaded wastewater because the parameters of the process can be adjusted in a simple way, so that this is the widely used biological method in wastewater treatment. Due to the fact that the different sludge substances have complicated structures and the solid content, temperature and shear stress influence the rheological properties, quantitative characterization has many difficulties [4, 10-12]. Solid concentration was found to be one of the critical parameters (beside the temperature) in determining the rheological characteristics of mixed sludge by Baroutian et al. [13].

The Herschel-Bulkley model is applied primarily to describe rheological sludge behaviour in the case of high solid concentrations, while Bingham's model is more frequently adapted to 
the description of the weakly concentrated sludge from aeration tanks of WWTPs [9, 14].

The main aim of this study was to investigate, how the own applied rheology model influences the predicted friction factor $(f)$ and loss coefficient $(\xi)$ of an elbow with an $R / D=1$ relative radius of curvature. For our research the rheological data of sludge were taken from a literature source. Guibaud et al. [9] measured the rheology of activated sludge from WWTPs aeration tanks. Three of the seven above-mentioned rheological models were chosen and these models were fit to the presented rheograms of activated sludge samples at different TSS (total suspended solids) contents. CFD simulations were carried out with the determined rheological parameters in one given pipe geometry; thereafter the computed friction factors, loss coefficients and pressure drops of the elbow were compared.

\section{Materials and methods}

\subsection{Rheological measurements}

In their study, Guibaud et al. [9] reported measurement data of activated fresh sludge from WWTPs aeration tanks with different TSS contents. For determining the rheological parameters they were used a PAAR Physica system MC100 rotational rheometer coupled with an US200 Software, which consist of a coaxial cylindrical device with double gap. The temperature was constant $\left(20 \pm 2{ }^{\circ} \mathrm{C}\right)$; the sample volume was $17 \mathrm{ml}$ for each measurements. The investigated shear rate range was $1-5001 / \mathrm{s}$, so laminar shear flow conditions were ensured during the measurements. The measured rheograms had a very low hysteresis surface. The same sample origin was diluted or concentrated to achieve three different TSS contents for the same sludge (7.4 g/l; $6.2 \mathrm{~g} / 1 ; 3.6 \mathrm{~g} / \mathrm{l})$.

\subsection{Rheological models}

Based on the literature recommendation $[13,15]$ three rheological model were fit to the measured data: the Ostwald (power-law PL), the Bingham (B) and the Herschel-Bulkley (HB) models. The describing equations are the followings:

$$
\begin{gathered}
\tau=k \dot{\gamma}^{n}, \\
\tau=\tau_{0 B}+\mu_{B} \dot{\gamma}, \\
\tau=\tau_{0 H B}+\mu_{H B} \dot{\gamma}^{n_{H B}},
\end{gathered}
$$

where $\tau$ is the shear stress, $\dot{\gamma}$ is the shear rate, $k$ is the flow consistency index in case of power-law model, $\tau_{0 B}$ and $\tau_{0 H B}$ are the yield stresses, $\mu_{B}$ and $\mu_{H B}$ are the dynamic viscosities of Bingham and Herschel-Bulkley fluids, respectively, and $n$ and $n_{H B}$ are the flow behaviour indices of PL and HB liquids.

\subsection{Numerical method}

The 3D structured numerical mesh (generated in ICEM CFD, see Fig. 1) included $1.2 \mathrm{~m}$ cells which earlier proved to be satisfactory, considering that the results were compared with own

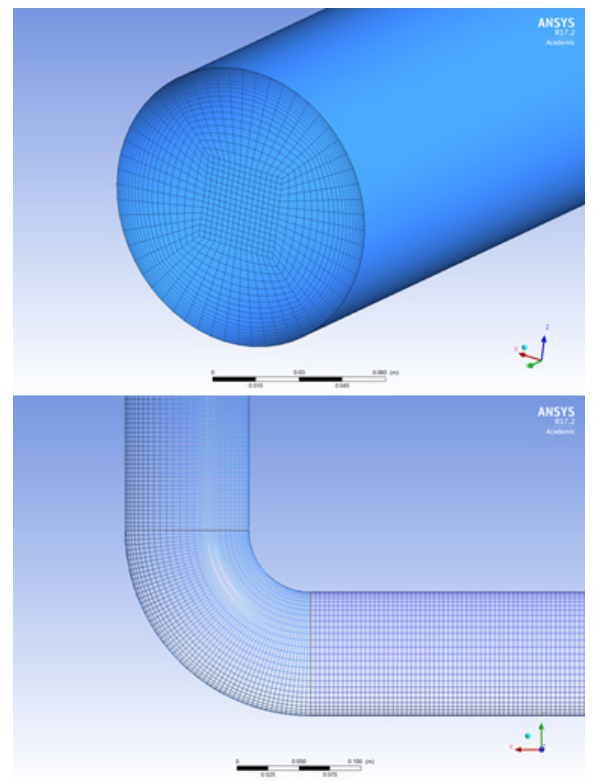

Fig. 1 3D structured numerical mesh

laboratory measurements [16]. At the inlet the fully developed turbulent velocity profile for Newtonian fluids [7], at the outlet the average static pressure were prescribed as boundary conditions. The pipe was modelled as a no slip, hydraulically smooth wall. The SST turbulence model was used, which was tested for non-Newtonian flows [7]. Steady state computations were performed with the commercial ANSYS-CFX 17.2 software; high-resolution spatial scheme was used for all equations. The software solves the Reynolds-averaged Navier-Stokes equations, the continuity equation, and the transport equations associated with the actual turbulence model.

It has been previously demonstrated by the authors [7] that using a turbulence model at laminar flow has no negative influence to the results. This is due to that the software automatically "switches off" the turbulence model in case of laminar flow conditions.

Additional straight pipes of 50D length were added to the upstream and 10D length to the downstream sides to allow proper boundary conditions (see Fig. 2). This length for the upstream section was adequate [7], and made the model suitable to verify the accuracy of our results in a simple, good controlled way.

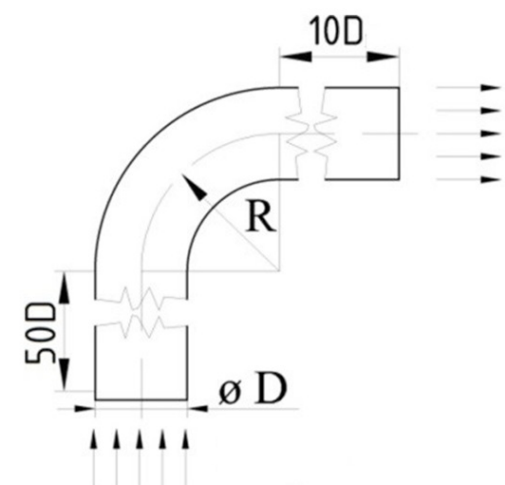

Fig. 2 Sketch of the geometry 


\subsection{Definitions}

The friction factor $(f)$ was calculated from the pressure drop in a $1 \mathrm{D}$ length straight pipe section before the fitting, where the flow was already developed:

$$
f=\frac{\Delta p}{\frac{L}{D} \frac{\rho}{2} \bar{v}^{2}}
$$

in which $\Delta p$ is the total pressure drop in the pipe section, $\rho$ is the fluid density (which was approximated with the water's density), $L$ is the length of the section, $D$ is the diameter of the pipe and $\bar{v}$ is the average velocity.

The loss coefficient $(\xi)$ was defined as the non-dimensional difference in total pressure caused by the fitting:

$$
\xi=\frac{\Delta p_{e}}{\frac{\rho}{2} \bar{v}^{2}}
$$

in which $\Delta p_{e}$ is the total pressure drop caused by the element. It was calculated between the beginning of the fitting and a plane after the elbow in 9D distance. The loss caused by the wall friction was subtracted from it but the forward disturbance of the fitting was taken into consideration. (It was verified by the authors that beyond 9D the forward impact of the elbow is negligible because there the $\Delta p_{e}$ changes less than $5 \%$.)

Theoretically, the Reynolds-number is the ratio of inertial forces to viscous forces, for Newtonian fluids is given as $R e=v D \rho / \mu$. For laminar and fully developed flow, the Darcy friction factor $\left(f_{D}=64 / R e\right)$ is defined, which is generally given for fluids independent of their viscosity characteristic [17]. For pipe flow Metzner and Reed [18] introduced a modified Reynolds-number valid for PL fluids. In addition, Madlener et al. [17] introduced an extended version of the generalized Reynolds-number $\left(R e_{g e n}\right)$ for PL, B or HB type of fluids as well.

Based on their studies in the case of the PL fluids the generalized Reynolds-number is defined as:

$$
R e_{\text {gen_- } P L}=\frac{\bar{v}^{2-n} D^{n} \rho}{8^{n-1} k\left(\frac{3 n+1}{4 n}\right)^{n}}
$$

for Bingham liquids:

$$
\operatorname{Re}_{\text {gen }_{-} B}=\frac{\bar{v} D \rho}{\frac{\tau_{0 B}}{8}\left(\frac{D}{\bar{v}}\right)+\mu_{B}\left(\frac{3 m+1}{4 m}\right)},
$$

with

$$
m_{B}=\frac{\mu_{B}(8 \bar{v} / D)}{\tau_{0 B}+\mu_{B}(8 \bar{v} / D)}
$$

and for Herschel-Bulkley (HB) fluids:

$$
R e_{\text {gen_HB }}=\frac{\bar{v}^{2-n_{H B}} D^{n_{H B}} \rho}{\frac{\tau_{0 H B}}{8}\left(\frac{D}{\bar{v}}\right)^{n_{H B}}+8^{n_{H B}-1} \mu_{H B}\left(\frac{3 m+1}{4 m}\right)^{n_{H B}}},
$$

with

$$
m_{H B}=\frac{n_{H B} \mu_{H B}(8 \bar{v} / D)^{n_{H B}}}{\tau_{0 H B}+\mu_{H B}(8 \bar{v} / D)^{n_{H B}}}
$$

where $D$ is the diameter of the pipe, $\rho$ is the fluid density, $\bar{v}$ is the average velocity, $k$ is the flow consistency index in case of power-law model, $n$ is the flow behaviour index, $\tau_{0}$ is the yield stress and $\mu$ is the dynamic viscosity; furthermore $m$ is the local gradient of the shear stress-shear rate in a log-log diagram.

The friction factor traditionally depends on the Reynoldsand Hedström-numbers (He) [19]. Besides, in the case of Bingham fluids the Bingham-number ( $\mathrm{Bi}$ ) can also be defined, as the ratio of the previous two dimensionless specific numbers:

$$
\begin{gathered}
H e=\frac{D^{2} \rho \tau_{0}}{\mu_{B}^{2}} ; \\
B i=\frac{H e}{\operatorname{Re}}=\frac{\tau_{0} D}{\mu_{B} \bar{v}},
\end{gathered}
$$

with the previous annotations. (The $\mathrm{He} / \mathrm{Re}$ dimensionless parameter is generally used by HB fluids as well, but in these cases the ratio is not called as $B i$-number.)

\section{Results \\ 3.1 Apparent viscosity}

The apparent viscosity is by definition the ratio of the shear stress and shear rate. Based on the measured data [9] there is a decrease in the material apparent viscosity when the strain rate is increased (see Fig. 3), so shear-thinning model can be suitable to describe the rheology.

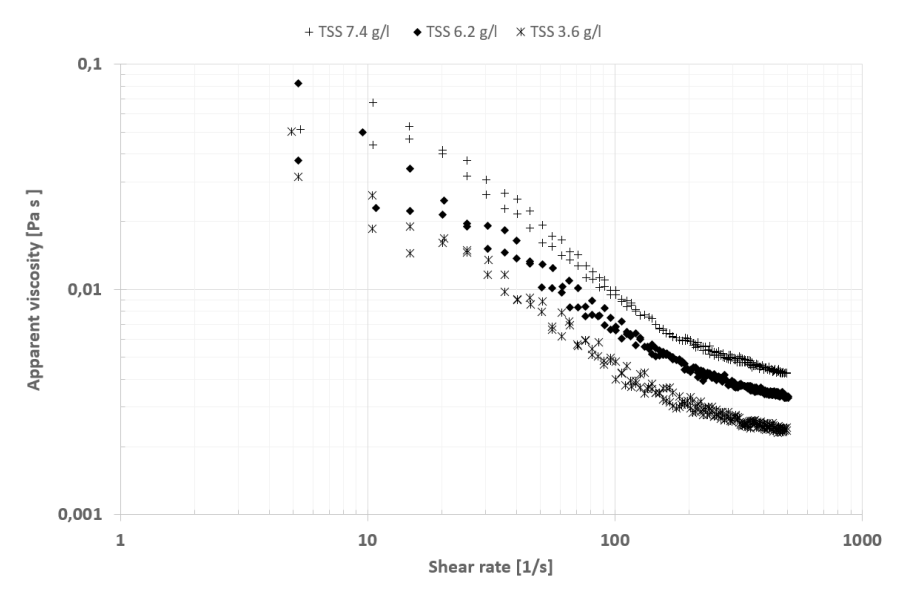

Fig. 3 Apparent viscosity at different TSS contents

\subsection{Rheological parameters}

All the three previously specified models were fit to the measured three rheograms. These fits were performed using linear and nonlinear (trust region reflective) least squares algorithms in MATLAB software.

The specified rheological parameters and the coefficient of determination $\left(R^{2}\right)$ of the fits can be seen in Table 1. The least good fit was experienced by the power-law model suggesting that the $\tau_{0}$ yield stress is not negligible. Though the HB model 
Table 1 Fit rheological parameters and the coefficients of determination $\left(R^{2}\right)$

\begin{tabular}{|c|c|c|c|c|c|}
\hline \multicolumn{6}{|c|}{ Parameters of the power-law model } \\
\hline \multicolumn{2}{|c|}{ TSS $7.4 \mathrm{~g} / 1$} & \multicolumn{2}{|c|}{ TSS $6.2 \mathrm{~g} / 1$} & \multicolumn{2}{|c|}{ TSS $3.6 \mathrm{~g} / 1$} \\
\hline $\mathbf{n}$ & $\mathbf{k}$ & $\mathbf{n}$ & $\mathbf{k}$ & $\mathbf{n}$ & $\mathbf{k}$ \\
\hline$[-]$ & {$\left[\mathrm{Pa} \mathrm{s}^{\mathrm{n}}\right]$} & {$[-]$} & {$\left[\mathrm{Pa} \mathrm{s}^{\mathrm{n}}\right]$} & {$[-]$} & {$\left[\mathrm{Pa} \mathrm{s}^{\mathrm{n}}\right]$} \\
\hline 0.32152 & 0.24105 & 0.39989 & 0.12023 & 0.41398 & 0.07649 \\
\hline $\mathbf{R}^{2}$ & & $\mathbf{R}^{2}$ & & $\mathbf{R}^{2}$ & \\
\hline 0.9613 & & 0.9579 & & 0.9515 & \\
\hline \multicolumn{6}{|c|}{ Parameters of the Bingham model } \\
\hline \multicolumn{2}{|c|}{ TSS $7.4 \mathrm{~g} / 1$} & \multicolumn{2}{|c|}{ TSS $6.2 \mathrm{~g} / 1$} & \multicolumn{2}{|c|}{ TSS $3.6 \mathrm{~g} / 1$} \\
\hline $\begin{array}{c}\boldsymbol{\mu}_{\mathrm{B}} \\
{[\mathrm{Pa} \mathrm{s}]}\end{array}$ & $\begin{array}{c}\tau_{\mathbf{0 B}} \\
{[\mathrm{Pa}]}\end{array}$ & $\begin{array}{c}\boldsymbol{\mu}_{\mathbf{B}} \\
{[\mathrm{Pa} \mathrm{s}]}\end{array}$ & $\begin{array}{c}\tau_{\mathbf{0 B}} \\
{[\mathrm{Pa}]}\end{array}$ & $\begin{array}{c}\mu_{\mathrm{B}} \\
{[\mathrm{Pa} \mathrm{s}]}\end{array}$ & $\begin{array}{c}\tau_{\mathbf{0 B}} \\
{[\mathrm{Pa}]}\end{array}$ \\
\hline 0.00279 & 0.66580 & 0.00245 & 0.42793 & 0.00179 & 0.27223 \\
\hline $\mathbf{R}^{2}$ & & $\mathbf{R}^{2}$ & & $\mathbf{R}^{2}$ & \\
\hline 0.968 & & 0.984 & & 0.982 & \\
\hline \multicolumn{6}{|c|}{ Parameters of the Herschel-Bulkley model } \\
\hline \multicolumn{2}{|c|}{ TSS $7.4 \mathrm{~g} / 1$} & \multicolumn{2}{|c|}{ TSS $6.2 \mathrm{~g} / 1$} & \multicolumn{2}{|c|}{ TSS $3.6 \mathrm{~g} / 1$} \\
\hline $\begin{array}{c}\boldsymbol{\mu}_{\mathrm{HB}} \\
{\left[\mathrm{Pa} \mathrm{s}^{\mathrm{n}}{ }_{\mathrm{HB}}\right]}\end{array}$ & $\begin{array}{c}\tau_{0 \mathrm{HB}} \\
{[\mathrm{Pa}]}\end{array}$ & $\begin{array}{c}\boldsymbol{\mu}_{\mathrm{HB}} \\
{\left[\mathrm{Pa} \mathrm{s}^{\mathrm{n}}{ }_{\mathrm{HB}}\right]}\end{array}$ & $\begin{array}{c}\tau_{0 \mathrm{HB}} \\
{[\mathrm{Pa}]}\end{array}$ & $\begin{array}{c}\boldsymbol{\mu}_{\mathrm{HB}} \\
{\left[\mathrm{Pa} \mathrm{s}^{\mathrm{n}}{ }_{\mathrm{HB}}\right]}\end{array}$ & $\begin{array}{l}\tau_{0 \mathrm{HB}} \\
{[\mathrm{Pa}]}\end{array}$ \\
\hline 0.00050 & 0.76617 & 0.00178 & 0.44775 & 0.00090 & 0.30158 \\
\hline $\mathbf{R}^{2}$ & $\mathbf{n}_{\mathrm{HB}}[-]$ & $\mathbf{R}^{2}$ & $\mathbf{n}_{\mathrm{HB}}[-]$ & $\mathbf{R}^{2}$ & $\mathbf{n}_{\mathrm{HB}}[-]$ \\
\hline 0.975 & 1.27279 & 0.984 & 1.04982 & 0.983 & 1.10773 \\
\hline
\end{tabular}

has three parameters, there was no significant difference between the coefficient of determination of HB and B rheological fitting.

\subsection{Friction factor}

There are many explicit forms of laminar friction factor for $\mathrm{B}$ and HB fluids. For instance in case of laminar flow of Bingham plastic fluids friction factor is given by the Buckingham-Reiner equation $\left(f_{B R}\right)$, where $f_{B R}$ is the function of $R e$ and $B i$ [20]. For Herschel-Bulkley laminar flow Swamee and Aggarwalt give an explicit equation for friction $\left(f_{S}\right)$, which is also $R e$ and $H e / R e$ dependent [21]. (It should be noted that the non-dimensional numbers used are individually defined by the different authors in these works.) The difference between our calculated friction factors and the $f_{B R}$ was below $3 \%$ by the B fluids; and was not more that $15 \%$ by HB model. The calculated friction factors as the function of the traditionally defined $R e$ showed good accordance with the literature; the outlined pattern (the markers are around lines) of the laminar friction factor were separated by the He-number (see Fig 5.) [22-24]. In case of PL fluid (when $\mathrm{He}$ is zero) the calculated friction factor values were on the 64 / Re line.

These predicted friction factors also can be presented as the function of the $R e_{\text {gen }}$. As expected, introducing this generalized $R e_{\text {gen }}$ arranges the calculated friction factors to $f_{D}=64 / R e_{\text {gen }}$ curve in case of laminar flow conditions (see Fig. 6). One of the most interesting aspect of this graph is that an arranged layout can be observed in turbulent conditions as well.

For turbulent non-Newtonian flows there are relatively few explicit forms for the friction factor. Tomita evaluated the

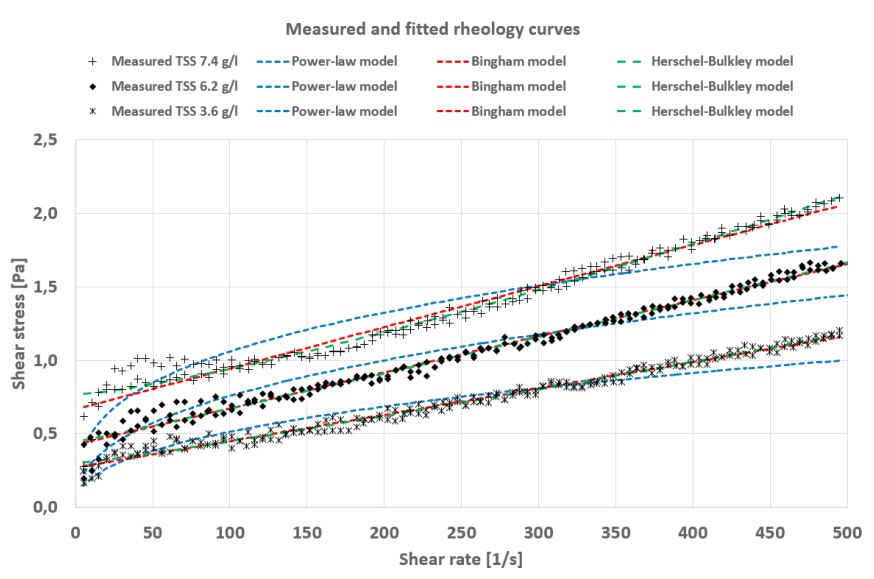

Fig. 4 Measured and fit rheograms at different TSS contents:

$$
+7.4 \mathrm{~g} / \mathrm{l} ; \bullet 6.2 \mathrm{~g} / \mathrm{l} ; \text { * } 3.6 \mathrm{~g} / \mathrm{l} \text {; }
$$

blue: fit power-law; red: fit Bingham; green: fit Herschel-Bulkley model.

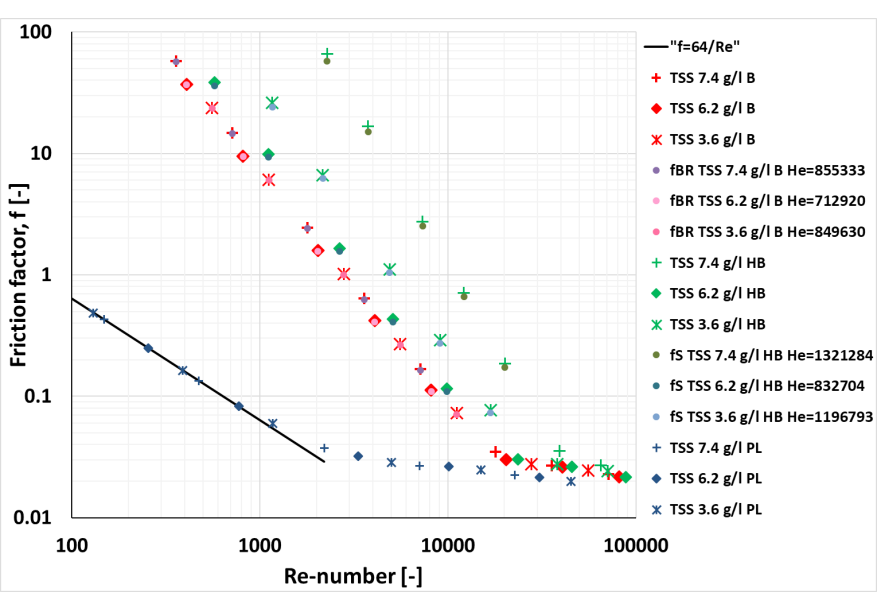

Fig. 5 Calculated and analytical friction factors as the function of the $R e$-number;

Calculated:+ 7.4 g/l; 6.2 g/l; * 3.6 g/1; red: B; green: HB; blue: PL model Analytical: $f_{B R}$ : Buckingham-Reiner friction factor [20], B model; $f_{S}$ : friction factor by Swamee [21], HB model

coefficients of pipe friction losses for power-law fluids (with the flow behaviour index between $n=0.2-0.9$ ) [25]. The Tomita friction factor $\left(f_{t}\right)$ includes the rheology of the fluid by the extended Tomita Reynolds-number $\left(R e_{T}\right)$. Turbulent friction factors (including the Tomita's) were experimentally examined by Leal et al. [26], and it was demonstrated by the authors that the formulism of Tomita a little bit overestimates the friction factor. It can be seen on Fig. 6 that our calculated values were also below the $f_{t}$, showing the same tendency.

\subsection{Laminar-turbulent transition}

The laminar-turbulent transition range appeared to shift as the $H e$ value changes in case of using the traditional $R e$ definitions [22]. Although the He-numbers changed only one order of magnitude (were between $7 \times 10^{5}-1.3 \times 10^{6}$ ) in our simulations, this was recognisable in our results, shown in Fig. 5.

On the other hand, the traditional (also called Hedström) technique has many limitations, see e.g. $[17,27,28]$. From the data in 


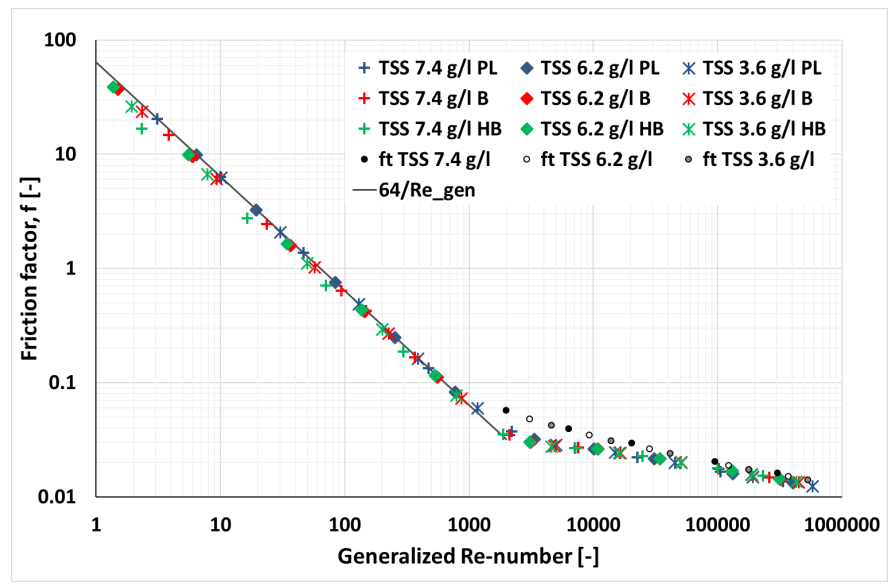

Fig. 6 Calculated and analytical friction factor as the function of the generalized $R e$-number

+7.4 g/l; 6.2 g/l; * 3.6 g/l; blue: PL; red: B; green: HB model; black line: Darcy friction factor $f_{D}=64 / R e_{\text {gen }}$; circles: Tomita friction factor $f_{t}[25]$;

Fig. 6, it is apparent that introducing the generalized $R e_{\text {gen }}$ seems to be an appropriate tool to get the locus of the transition range at $R e_{\text {gen }} \approx 2200$. In addition, Fig. 6 provides that $R e_{\text {gen }}$ is applicable both of the three rheological models.

\subsection{Loss coefficient of the elbow}

Fig. 7 shows the dimensionless loss coefficient $(\xi)$ of the elbow calculated with the three different models (with blue, red and green colours), with the three different TSS contents (with different symbols). It is apparent that $R e_{\text {gen }}$ covered the properties caused by the different concentrations here, so that curves of the same colour cannot be distinguished.

Because of the different $R e_{\text {gen }}$ values at the various rheological models, the quantitative comparison was not relevant. Even so it can be stated that the results by the Bingham and Herschel-Bulkley models showed good agreement, while the power-law model gave distinct values for the loss coefficient in the region of $R e_{\text {gen }}=90-2100$.

\subsection{Pressure drop caused by the elbow}

For adequate sizing of hydraulic systems in WWTPs the pressure drop caused by the elements has to be known at different velocities (see Fig. 8). In our work the non-Newtonian pressure losses were in every point above those calculated with water, which was also computed and considered as a reference. In the laminar region (where $R e_{\text {gen }}<2200$; which means $v \approx 0-0.5 \mathrm{~m} / \mathrm{s}$ ) there was no more than $15 \mathrm{~Pa}$ difference between the Newtonian and non-Newtonian losses (including all the three rheology models).

In contrast at turbulent flow conditions there were remarkable differences between the water and the sludge. The highest difference in pressure drop was between the HB and water fluids: it was around $2600 \mathrm{~Pa}$ at $10 \mathrm{~m} / \mathrm{s}$ velocity. At lower velocities the non-Newtonian pressure drop was 30-98 \% higher, than that of

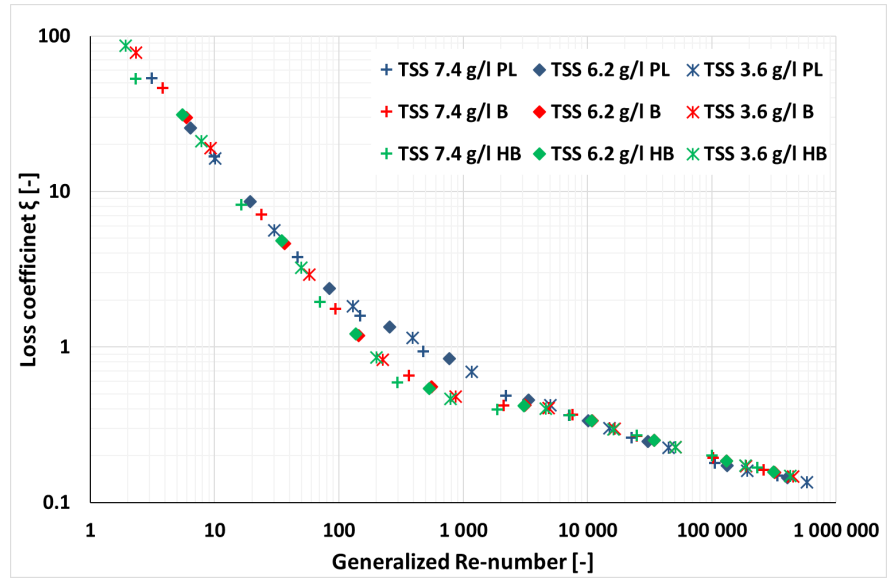

Fig. 7 Calculated loss coefficients of an elbow with an $R / D=1$ relative radius of curvature as the function of the generalized $R e$-number

$+7.4 \mathrm{~g} / \mathrm{l} ; \quad 6.2 \mathrm{~g} / \mathrm{l} ;$ * $3.6 \mathrm{~g} / \mathrm{l}$; blue: PL; red: B; green: HB model;

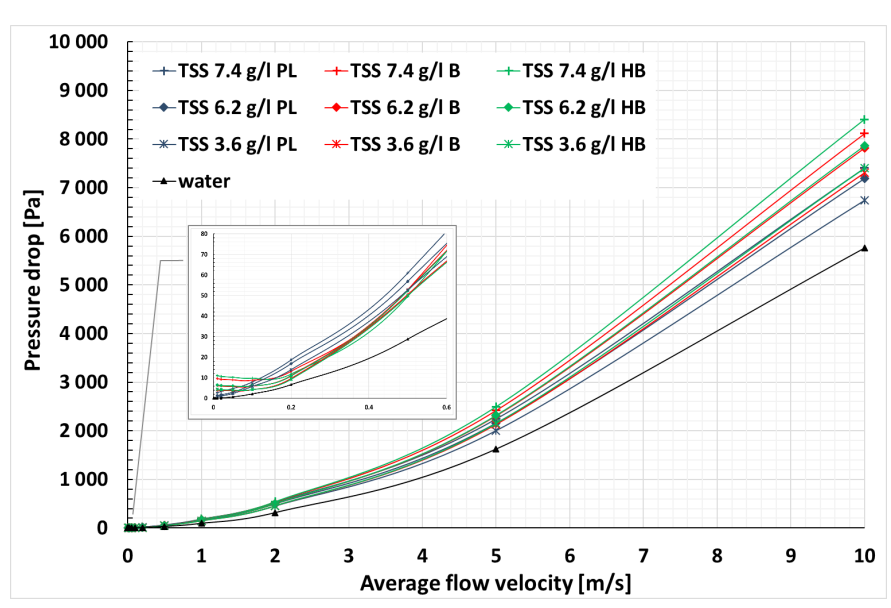

Fig. 8 Pressure drop on the elbow as the function of the average flow velocity; highlighted the laminar region.

$+7.4 \mathrm{~g} / \mathrm{l} ; \quad 6.2 \mathrm{~g} / \mathrm{l} ; * 3.6 \mathrm{~g} / \mathrm{l}$; blue: PL; red: B; green: HB model;

the water. These findings are in good agreement with Ratkovich et al. [1] and in contrast with the statement of Leal at al. [26], who concluded that the pressure drop of an elbow can be calculated using the loss coefficients for Newtonian fluids. (It should be noted that their investigation was carried out in a very low velocity range, where the flow was supposedly laminar.)

To take a closer look at Fig. 8 it could be observed that the $\mathrm{B}$ and HB curves at a given TSS content were very close to each other: the highest $-3 \%$ - difference was in the transition region. On the other hand, the differences between the PL and the other two models were also not too significant by the lower TSS contents: they were no more than $9 \%$. By the $7.4 \mathrm{~g} / 1$ TSS content in high velocity range 10-12\% difference can be observed, here the calculation based on PL model was expected to underestimate the losses.

The higher the TSS content was, the more pressure drop was caused by the elbow, as can be seen in Fig. 9. In reviewing the literature, similar data were given previously for pipe losses $[29,30]$ but there much less information was given about the pressure drop caused by pipe fittings. 


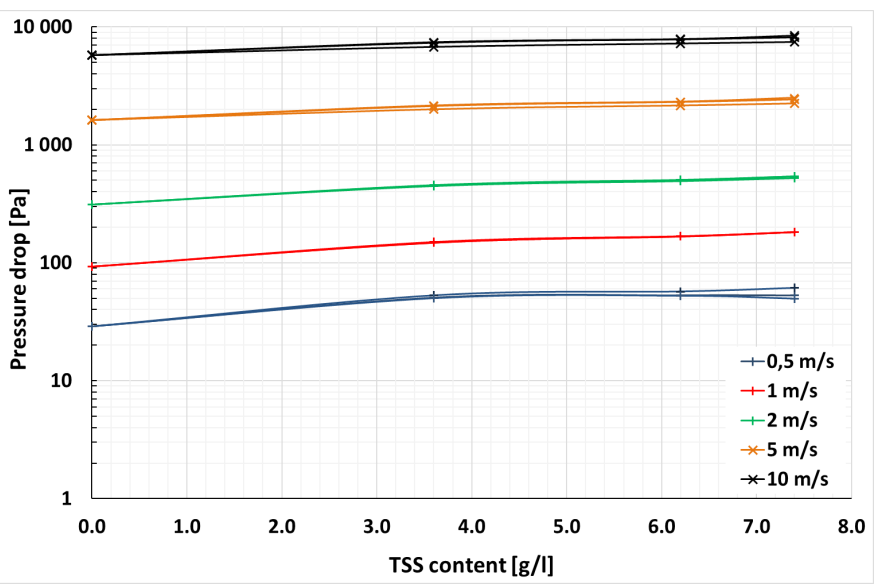

Fig. 9 Pressure drop as the function of the TSS content in case of different velocity values (turbulent flow conditions) (The zero TSS value belongs to the water.)

\section{Conclusions}

Due to increasing urban populations and tightening of environmental rules wastewater treatment plants are under pressure to treat larger volumes of sludge. In this field there is still much to do, e.g. to give better estimation of the losses of pipes and elements. The present study has shown that the computational fluid dynamics codes seem to be suitable for such purposes.

The present study was designed to determine the effect of applied rheology models and the TSS content to the friction factor, to the loss coefficient and the pressure drop of a given elbow using CFD. Even though this investigation was carried out on the activated sludge, the results can be used in a wide range of the given dimensionless parameters.

The power-law, Bingham and Herschel-Bulkley models were fit to measured rheograms of activated sludge at three different TSS contents, which were reported by Guibaud et al. [9]. The best fit was achieved by the Herschel-Bulkley model.

Our findings suggested that among the many existing definitions the generalized Re-number $R e_{\text {gen }}$ arranges the friction factor values appropriately. Using the definition from the work of Madlener et al. [17] the laminar-turbulent transition zone was appeared at $R e_{\text {gen }} \approx 2200$. The computed friction factor values showed good agreement with the literature.

From the engineering point of view the major finding of our study was that the pressure loss caused by a pipe element was significantly higher in case of non-Newtonian flow than those with water. Our results complemented the existing literature with giving the pressure drop for sludge with different total suspended solid contents as well.

In our work the calculated pressure drops by the Bingham and the Herschel-Bulkley models were very close two each other. Considering that the numerical simulations applying Bingham model require less computing capacity (because it is described with only two parameters) it can be recommended to use the Bingham model for hydrodynamic simulations at similar rheological parameters. (The power-law model also can be applied by low TSS contents, but using of it not recommended by higher concentrations, because it supposedly underestimates the losses.)

The limitation of this study was that only one given material was investigated at three different relatively low (3.6 g/l -7.4 g/l) TSS content. The small range of Hedström-numbers also did not allow reaching general conclusions. A further study could assess the effect of $\mathrm{He}$ more precisely, taken into consideration a larger range of rheological and geometrical parameters.

\section{Acknowledgement}

The research reported in this paper was supported by the Higher Education Excellence Program of the Ministry of Human Capacities in the frame of Water science \& Disaster Prevention research area of Budapest University of Technology and Economics (BME FIKP-VÍZ).

\section{References}

[1] Ratkovich, N., Horn, W., Helmus, F. P., Rosenberger, S., Naessens, W. Nopens, I., Bentzen, T. R. "Activated sludge rheology: A critical review on data collection and modelling." Water Research. 47(2), pp. 463-482. 2013. https://doi.org/10.1016/j.watres.2012.11.021

[2] Singh, J., Rudman, M., Blackburn, H. M., Chryss, A., Pullum, L., Graham, L. J. W. "The importance of rheology characterization in predicting turbulent pipe flow of generalized Newtonian fluids." Journal of Non-Newtonian Fluid Mechanics. 232, pp. 11-21. 2016 https://doi.org/10.1016/j.jnnfm.2016.03.013

[3] Khandelwal, V., Dhiman, A., Baranyi, L. "Laminar flow of non-Newtonian shear-thinning fluids in a T-channel." Computers and Fluids. 108, pp. 79-91. 2015.

https://doi.org/10.1016/j.compfluid.2014.11.030

[4] Seyssiecq, I., Ferrasse, J.-H., Roche, N. "State-of-the-art: rheological characterisation of wastewater treatment sludge." Biochemical Engineering Journal. 16(1), pp. 41-56. 2003. https://doi.org/10.1016/S1369-703X(03)00021-4

[5] Unluturk, S., Atilgan, M. R., Handan Baysal, A., Tari, C. "Use of UV-C radiation as a non-thermal process for liquid egg products (LEP)." Journal of Food Engineering. 85(4), pp. 561-568. 2008. https://doi.org/10.1016/j.jfoodeng.2007.08.017

[6] Telis-Romero, J., Telis, V. R. N., Yamashita, F. "Friction factors and rheological properties of orange juice." Journal of Food Engineering. 40(1-2), pp. 101-106. 1999.

https://doi.org/10.1016/S0260-8774(99)00045-X

[7] Csizmadia, P. "Sürüzagy keveröben lezajló áramlási folyamatok kisérleti és numerikus vizsgálata." (Experimental and numerical investigation of the flow field inside a dense slurry mixer.) PhD Thesis, Budapest University of Technology and Economics, 2016. [Online]. Available from: http://hdl.handle.net/10890/5312 [Accessed: 1st February 2018]

[8] Eshtiaghi, N., Markis, F., Yap, S. D., Baudez, J.-C., Slatter, P. "Rheological characterisation of municipal sludge: A review." Water Research. 47(15), pp. 5493-5510. 2013.

https://doi.org/10.1016/j.watres.2013.07.001

[9] Guibaud, G., Dollet, P., Tixier, N., Dagot, C., Baudu, M. "Characterisation of the evolution of activated sludges using rheological measurements." Process Biochemistry. 39(11), pp. 1803-1810. 2004. https://doi.org/10.1016/j.procbio.2003.09.002 
[10] Yeneneh, A. M., Hong, E., Sen, T. K., Kayaalp, A., Ang, H. M. "Effects of Temperature, Polymer Dose, and Solid Concentration on the Rheological Characteristics and Dewaterability of Digested Sludge of Wastewater Treatment Plant (WWTP)." Water, Air, and Soil Pollution. 227(119), pp. 1-14. 2016. https://doi.org/10.1007/s11270-016-2820-4

[11] Baudez, J. C., Slatter, P., Eshtiaghi, N. "The impact of temperature on the rheological behaviour of anaerobic digested sludge." Chemical Engineering Journal. 215-216, pp. 182-187. 2013. https://doi.org/10.1016/j.cej.2012.10.099

[12] Markis, F., Baudez, J.-C., Parthasarathy, R., Slatter, P., Eshtiaghi, N. "Rheological characterisation of primary and secondary sludge: Impact of solids concentration." Chemical Engineering Journal. 253, pp. 526-537. 2014. https://doi.org/10.1016/j.cej.2014.05.085

[13] Baroutian, S., Eshtiaghi, N., Gapes, D. J. "Rheology of a primary and secondary sewage sludge mixture: Dependency on temperature and solid concentration." Bioresource Technology. 140, pp. 227-233. 2013. https://doi.org/10.1016/j.biortech.2013.04.114

[14] Khalili Garakani, A. H., Mostoufi, N., Sadeghi, F., Hosseinzadeh, M., Fatourechi, H., Sarrafzadeh, M. H., Mehrnia, M. R. "Comparison between different models for rheological characterization of activated sludge." Iranian Journal of Environmental Health Science \& Engineering. 8(3), pp. 255-264. 2011.

[15] Baudez, J.-C., Gupta, R. K., Eshtiaghi, N., Slatter, P. "The viscoelastic behaviour of raw and anaerobic digested sludge: Strong similarities with soft-glassy materials." Water Research. 47(1), pp. 173-180. 2013. https://doi.org/10.1016/j.watres.2012.09.048

[16] Csizmadia, P., Hös, Cs. "CFD-based estimation and experiments on the loss coefficient for Bingham and power-law fluids through diffusers and elbows." Computers and Fluids. 99, pp. 116-123. 2014. https://doi.org/10.1016/j.compfluid.2014.04.004

[17] Madlener, K., Frey, B., Ciezki, H. K. "Generalized Reynolds number for non-Newtonian fluids." Progress in Propulsion Physics. 1, pp. $237-250.2009$. https://doi.org/10.1051/eucass/200901237

[18] Metzner, A. B., Reed, J. C. "Flow of Non-Newtonian Fluids-Correlation of the Laminar, Transition, and Turbulent-flow Regions." AIChe Journal. 1(4), pp. 434-440. 1955. https://doi.org/10.1002/aic.690010409

[19] Hedström, B. O. A. "Flow of Plastic Materials in Pipes." Industrial \& Engineering Chemistry. 44(3), pp. 651-656. 1952. https://doi.org/10.1021/ie50507a056
[20] Swamee, P. K., Aggarwal, N. "Explicit equations for laminar flow of Bingham plastic fluids." Journal of Petroleum Science and Engineering. 76(3-4), pp. 178-184. 2011. https://doi.org/10.1016/j.petrol.2011.01.015

[21] Swamee, P. K., Aggarwal, N. "Explicit equations for laminar flow of Herschel-Bulkley fluids." The Canadian Journal of Chemical Engineering. 89(6), pp. 1426-1433. 2011. https://doi.org/10.1002/cjce.20484

[22] Hanks, R. W., Dadia, B. H. "Theoretical analysis of the turbulent flow of non-Newtonian slurries in pipes." AIChE Journal. 17(3), pp. 554-557. 1971. https://doi.org/10.1002/aic.690170314

[23] Chhabra, R. P. Richardson, J. F. "Non-Newtonian Flow and Applied Rheology: Engineering Applications." (2nd ed.). Elsevier Butterworth-Heinemann, Oxford, UK. 2008.

[24] Csizmadia, P., Hős, Cs. "Predicting the friction factor in straight pipes in the case of Bingham plastic and the power-law fluids by means of measurements and CFD simulation." Periodica Polytechnica Chemical Engineering. 57(1-2), pp. 79-83. 2013. https://doi.org/10.3311/PPch.2174

[25] Tomita, Y. "A Study on Non-Newtonian Flow in Pipe Lines." Bulletin of JSME. 2(5), pp. 10-16. 1959. https://doi.org/10.1299/jsme1958.2.10

[26] Leal, A. B., Calçada, L. A., Scheid, C. M. "Non-Newtonian Fluid Flow in Ducts: Friction Factor and Loss Coeficients." In: 2nd Mercosur Congress on Chemical Engineering, 4th Mercosur Congress on Process Systems Engineering, Proceedings of ENPROMER 2005, Rio de Janeiro, Brasil, Aug. 14-18, 2005. pp. 1-10.

[27] Wilson, K. C., Thomas, A. D. "Analytic Model of Laminar-Turbulent Transition for Bingham Plastics." The Canadian Journal of Chemical Engineering. 84(5), pp. 520-526. 2006. https://doi.org/10.1002/cjce.5450840502

[28] Haldenwang, R., Sutherland, A. P. N., Fester, V. G., Holm, R., Chhabra, R. P. "Sludge pipe flow pressure drop prediction using composite power-law friction factor - Reynolds number correlations based on different non-Newtonian Reynolds numbers." Water SA. 38(4), pp. 615-622. 2012.

[29] Eftekharzadeh, S., Marx, J. J., Harrison, D. "Sludge Rheology and Non-Newtonian Pipeline Hydraulics." WEF/AWWA Joint Residuals and Biosolids Management. pp. 36-48. 2007.

[30] Füreder, K., Svardal, K., Krampe, J., Kroiss, H. "Rheology and friction loss of raw and digested sewage sludge with high TSS concentrations: a case study." Water Science and Technology. 2017(1), pp. 276-286. 2018. https://doi.org/10.2166/wst.2018.111 